\title{
Aşil tendon rüptür cerrahisi sonrası fonksiyonel rehabilitasyon
}

\author{
Functional rehabilitation program after Achilles tendon repair
}

\author{
Filiz Can, Esra Ateş Numanoğlu
}

Hacettepe Üniversitesi, Sağlık Bilimleri Fakültesi, Fizyoterapi ve Rehabilitasyon Bölümü, Ankara

\begin{abstract}
Aşil tendon onarımı sonrası fonksiyonel rehabilitasyon programı, günümüzde cerrahi sonrası Aşil tendon rehabilitasyonunda yaygın olarak kullanılır. Bu program, geleneksel rehabilitasyon protokolündeki uzun süreli immobilizasyonun, eklem sertliği, kas atrofisi, tendokutanöz adhezyon ve derin ven trombozu gibi komplikasyonlara yol açması nedeniyle, bu riskleri azaltmak veya önlemek üzere geliştirilmiştir. Fonksiyonel rehabilitasyon, olabilen en erken dönemde ve hastanın tolere edebildiği ağılık aktarımı ile erken mobilizasyona ve fonksiyonel aktivitelere izin verilen bir rehabilitasyon programıdır. Bu programın en önemli prensibi olan erken ağırlık aktarımı ve fonksiyonel aktiviteler, Aşil tendonun vaskülaritesini arttırır; kollajen liflerin re-organizasyonunu ve re-oryantasyonunu sağlar; tendonun yapısını geliştirir ve olgunlaştırır. Geleneksel rehabilitasyon uygulamalarına göre klinik sonuçları daha iyidir ve hastanın güvenli bir şekilde eski aktivite seviyesine ve sporuna dönüşüne izin verir. Bu bölümde, Aşil tendon onarımı sonrası uygulanan fonksiyonel rehabilitasyon programının içeriği, cerrahi sonrası dönemden başlayarak spora dönüş dönemi dahil olmak üzere beş devre olarak anlatılmıştır.
\end{abstract}

Anahtar sözcükler: Aşil tendon rüptür cerrahisi; fonksiyonel rehabilitasyon; erken ağırlık aktarımı; spora dönüş
Functional rehabilitation program after Achilles tendon repair is now widely used in postoperative Achilles tendon rehabilitation. This program has been developed to reduce or prevent these risks due to long-term immobilization in the traditional rehabilitation protocol, complications such as joint stiffness, muscle atrophy, tendocutaneous adhesion, and deep vein thrombosis. Functional rehabilitation is a rehabilitation program that permits early mobilization and functional activities with the weight bearing that can be tolerated by the patient at the earliest possible time. The most important principle of this program, i.e. early weight bearing and functional activities; increases the vascularity of the Achilles tendon, enables re-organization and re-orientation of collagenous fibers, develops and matures the tendon structure. Clinical outcomes are better than traditional rehabilitation practices, and allows the patient to safely return to the former activity level and sport. In this section, the content of the functional rehabilitation program applied after the Achilles tendon repair is described as 5 periods including postoperative period and return to sports period.

Key words: Achilles tendon rupture surgery; functional rehabilitation; early weight bearing; return to sports

tendokutanöz adhezyon ve derin ven trombozu gibi komplikasyon risklerini en aza indirmek için, ilk olarak 1974 yılında Marti ve Weber, ameliyat sonrası fonksiyonel rehabilitasyon protokolünü tanımlamışlardır. Cerrahi sonrası erken dönemde, dikişlerin tendonun rüptürden korunması için yeterince güçlü olduğunu bulmuşlar ve tolere edilebilen en erken dönemde ilgili ekstremite üzerine ağırlık aktarımına ve fonksiyonel aktivitelere izin verilebileceğini bildirmişlerdir. ${ }^{[3]}$

1980'lerden itibaren, Aşil tendon onarımı sonrası rehabilitasyon protokolü kliniklerde kullanılmaya başlanmış ve günümüzde yaygın olarak kullanılan ve en çok tercih edilen bir protokol haline gelmiştir. ${ }^{[4,5]}$

- İletişim adresi: Prof. Dr. Filiz Can, Hacettepe Üniversitesi, Sağlık Bilimleri Fakültesi, Fizyoterapi ve Rehabilitasyon Bölümü, 06100 Sıhhiye, Ankara Tel: 0532 - 4575652 e-posta: filizcan2002@yahoo.com

- Geliș tarihi: 1 Ocak2018 Kabul tarihi: 1 Ocak 2018 
Çeşitli hayvan ve insan çalışmalarında, Aşil tendon yaralanmalarından sonra erken ağırlık aktarımının ve hareketin iyileşme için yararlı olduğu gösterilmiştir. Erken ağırık aktarımı, tendon karakteristiklerinin gelişmesine, kollajen liflerin olgunlaşması ve oryantasyonunun sağlanmasına ve tendon vaskülaritesinin artmasına yarar sağlamaktadır. Hayvan çalışmaları, onarılmış bir tendondaki erken ağırlık aktarımı, fonksiyonel yüklenme ve gerilimin, baldır kas kuvveti ve tendonun kuvvet ve vaskülaritesini geliştirdiğini, iyileşmenin erken döneminde enerji absorpsiyonu ve gerilmeye dayanıklılığını arttırdığını göstermiştir. ${ }^{[6-8]}$ Kangas ve ark.'nın insanlar üzerinde yaptıkları bir çalışmada, Aşil tendon onarımı yapılan 50 hastadan, erken ağırlık aktarımı ile fonksiyonel rehabilitasyon uygulanan hastaların tendon elongasyonunun daha az olduğu ve klinik sonuçlarının geleneksel rehabilitasyon uygulanan hastalara göre daha iyi bulunduğu belirtilmiştir. ${ }^{[9]}$ İnsanlar üzerinde yapılan diğer ileriye dönük ve randomize kontrollü çalışmalarda, immobilizasyon ile karşılaştırıldığında, cerrahi sonrası erken hareket ve ağırlık aktarımının ek riskler oluşturmadığı, kayıp iş günlerinde azalma sağladığı ve daha erken bir spora dönüş eğilimi olduğu bulunmuştur. ${ }^{[10-12]}$ Cerrahi sonrası rehabilitasyon protokollerinin incelendiği bir meta-analizde, akut Aşil tendonu rüptürünün cerrahi onarımından sonra erken ağırlık aktarımının, cerrahi sonrası erken dönemde yaşam kalitesini arttırdığı ve iyileşme üzerinde herhangi bir olumsuz etkisinin olmadığı bildirilmiş, geleneksel ve fonksiyonel rehabilitasyon programlarında yeniden rüptür oluşumunda fark görülmemiştir. ${ }^{[5]}$ Bununla birlikte, erken dönemde cerrahi sonrası ayak bileği mobilizasyonu ve fonksiyonel rehabilitasyonu kullanan ilk klinik çalışmalarda yeniden rüptür oluşumunun azaldığı belirtilmiştir.

Kerkhoffs ve ark. çalışmalarında, cerrahi sonrası erken dönemde parsiyel ağırlık aktarımı uyguladıkları hastalarında hastanede kalış ve spora dönüş sürelerinin belirgin bir biçimde azaldığını bulmuşlardır. ${ }^{[13]}$ McCormack ve Bovard, yaptıkları çalışmada, erken dönemde hasta memnuniyeti ve önceki spor seviyesine geri dönme zamanı ile ilgili olarak, tam ağırlık aktarımıyla fonksiyonel rehabilitasyonun splint ile immobilizasyondan daha üstün olduğunu bildirmişlerdir. Üstelik, geleneksel rehabilitasyon ile fonksiyonel rehabilitasyonda majör komplikasyonlardan yakınmada, önceki iş ve spor aktivitesine geri dönüş oranında hiçbir fark bulamamışlardır. Bu nedenle, akut Aşil tendon rüptürünün cerrahi onarımını takiben erken fonksiyonel rehabilitasyonun güvenli olduğu ve daha yüksek hasta memnuniyeti ve daha erken işe dönüş sağladığı sonucuna varmışlardır. ${ }^{[14]}$

\section{AŞIL TENDON ONARIMI SONRASI FONKSIYONEL REHABILITASYON}

Rehabilitasyon programı oluşturulurken, mutlaka yapılan cerrahi ve hastanın durumu göz önünde bulundurulmalı, programın kişiye özel olması gerektiği unutulmamalıdır.

Aşil tendon onarımı sonrası rehabilitasyonda genel prensipler:

- Cerrahi sonrası ağrı ve ödemi azaltmak.

- Onarılan tendonun bütünlüğüne ve iyileşme sürecine zarar vermeyecek şekilde hareketleri korumak.

- Cerrahiye ve hastanın durumuna göre olabilecek en erken dönemde ağırlık aktarımına ve fonksiyonel aktivitelere geçişi sağlamak.

- Cerrahi sonrası inhibisyonu önlenmek ve gastrocnemius ve soleus kasları ile antagonist kasların kuvvet dengesini sağlamak.

- Tüm alt ekstremitenin kuvvet, koordinasyon ve propriyosepsiyonunu geliştirmek.

- Yeniden yaralanma ve rüptür oluşumu riskini azaltmak.

- Güvenli bir şekilde eski aktivite seviyesine, iş ve spora dönüşü sağlamak. ${ }^{[15]}$

\section{Cerrahi sonrası Erken Dönem (İmmobilizasyon Süreci) (0-2 hafta)}

Cerrahi sonrası ilk iki hafta, ayak bileği cerrahın tercih ettiği bir derecede (genellikle tam ekin pozisyonunda) plantar fleksiyonda rijid bir splint'le sabitlenir. Hasta koltuk değneği veya yürüteç kullanarak ağırlık aktarmadan mobilize olur. Bu süreçte ödemi ve ağrııı azaltarak yara iyileşmesini uyarmak için koruma, dinlenme, buz uygulaması, kompresyon, elevasyon uygulamalarını içeren PRICE protokolü (Protection; Rest; Ice; Compression; Elevation) uygulanır.

Aşil tendon cerrahisi uygulanan hastalarda izometrik kuvvet ölçümü yapılan bir çalışmada, (plantar fleksör ile ekstansörlere $60^{\circ} /$ sn'de maksimum istemli kuvvet testi yapılarak) 24 (\%80 oranında) hastada, plantar fleksör ve ekstansörlerde izometrik kasılmada güç kaybı gösterilmiştir. Bütün hastalarda, plantar fleksörlerdeki kas kuvvet kaybı ekstansör kaslara göre daha büyüktür. Hastalarda, sağlam taraf ile karşılaştırıldığında, cerrahi olarak tedavi edilen taraftaki plantar fleksörlerin maksimum kuvveti $\% 76,2$ ve ekstansörlerinki ise \%88,6 olarak bulunmuştur. ${ }^{[16]}$ Heikkinen ve ark., Aşil tendon rüptür cerrahileri sonrası diğer taraf ile karşılaştıııldığında, etkilenen taraf Aşil tendonunda uzama, gastrocnemius ve soleus kasları kas kütlelerinde ve plantar fleksiyon kuvvetinde azalma görüldüğünü 


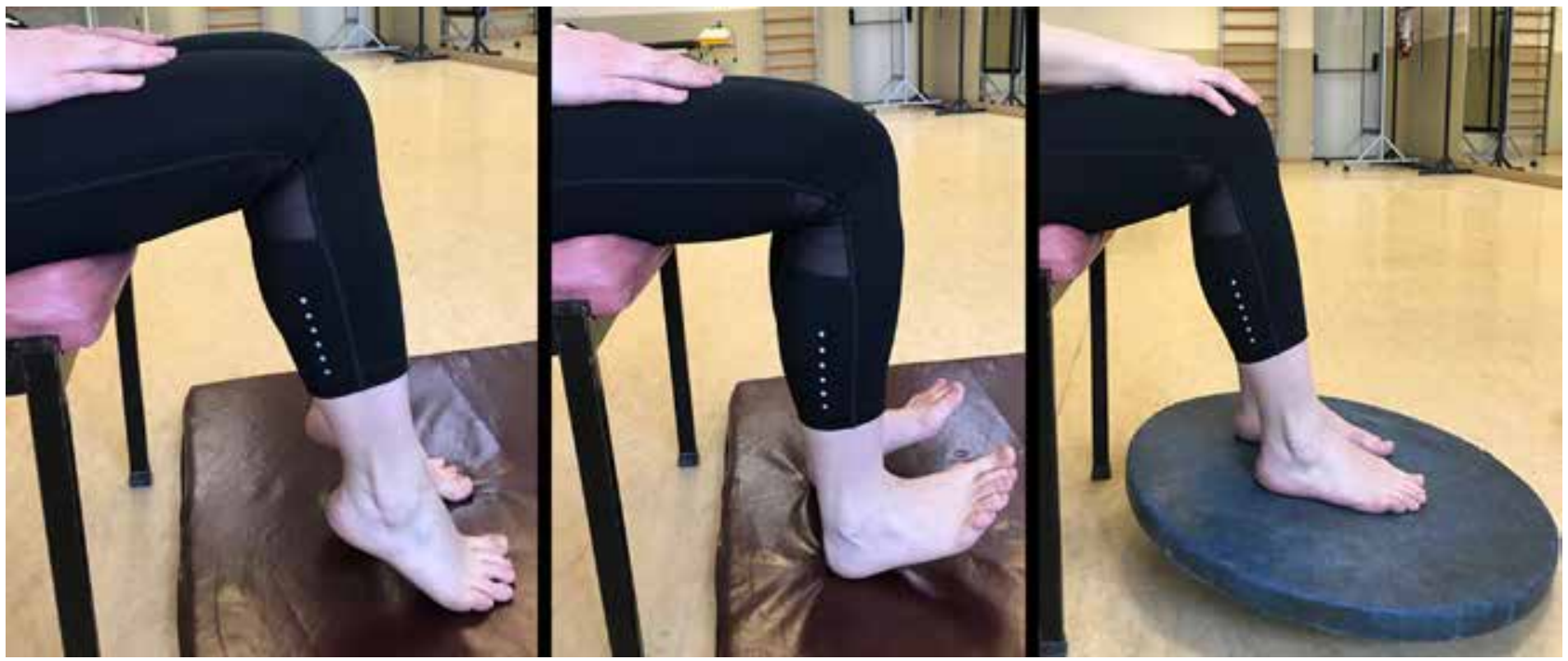

Şekil 1. Oturmada plantarfleksiyon, dorsifleksiyon ve wobble board egzersizleri.

belirtmişlerdir. ${ }^{[17]}$ Bu nedenle, cerrahi sonrası en erken dönemden itibaren, kas atrofısinin miktarını azaltmak için kuvvetlendirme egzersizlerine başlanmalıdır. Cerrahi sonrası ilk iki hafta daha güvenli olacağı için, dorsifleksiyon, inversiyon ve eversiyon yönlerinde izometrik egzersizlere başlanmalıdır. Bu dönemde, alt ekstremiteye yönelik diğer düz bacak kaldırma ve bacak abduksiyonu gibi kalça çevresi kaslara yönelik diğer aktif hareketler de iyileşmeyi hızlandırmakta ve fonksiyonlara erken dönüşü sağlamaktadır.

\section{Erken Dönem (2-6 Hafta)}

Erken dönemde amaç; ağrııı azaltmak, inflamasyonun kontrolünü sağlamak, normal eklem hareketlerini kazandırmak ve tam ağırlık aktarımını sağlamaktır.

Rijid splint'ten giyilip çıkarılabilen bir bota geçilir. Bot menteşeli ise, $20^{\circ}$ 'lik plantarfleksiyona yerleştirilir; menteşeli değilse yine yaklaşı $20^{\circ}$ 'lik plantarfleksiyon elde etmek için topuğa $2 \mathrm{~cm}$ yüksekliğinde kama yerleştirilir. Bot, ağırlık aktarımı yapılmayan egzersizler ve banyo (ağırlık aktarmadan) dışında bütün gün giyilmelidir.

Hastaya; ödem kontrolü için soğuk uygulama (buz, kriyoterapi), klasik masaj, zıt banyo, pnömatik kompresyon, elektrik stimülasyonu (enterfaransiyel akım ya da diadinami gibi) uygulanabilir. Ağrıyı azaltmada TENS gibi elektrik stimülasyon yöntemleri de kullanılabilir.

Erken ayak bileği mobilizasyonunun daha iyi fonksiyonel sonuçlar ortaya çıkardığı ve yaşam kalitesini arttırdığı çalışmalarla gösterilmiştir. ${ }^{[1,11,18]}$ Bu nedenle, 2. haftadan itibaren dereceli olarak, aralıklı açılardaki fleksiyondan nötral pozisyona kadar aktif dorsifleksiyon ve nötralin altında inversiyon ve eversiyon hareketleri yaptırılır. Eklem hareket açıklığını arttırmak için talokrural, subtalar, distal tibiofibular ve orta ayak eklemlerine manuel terapi tekniklerinden Grade I ve Grade II mobilizasyon yöntemleri, Aşil tendonuna yumuşak doku teknikleri ve skar bölgesine yönelik mobilizasyon teknikleri, nötrali geçmeyecek şekilde nazikçe dorsifleksiyona germe ve fleksibilite egzersizleri uygulanabilir. Bunun yanı sıra, ayak bileği için sınırlandırılan hareket aralığında, ayak ile daire çizme ya da harf çizme egzersizleri yapabilir.

Etkilenen alandaki kasların kuvvetlendirilmesi için dorsifleksiyon, inversiyon ve eversiyon yönlerindeki izometrik egzersizlere devam edilir. Kleinert ve ark. ${ }^{[19]}$, egzersiz bandına karşı dirençli aktif dorsifleksiyon hareketinin fleksör tendonların onarımından sonra yararIı olduğunu belirtmişlerdir. Bu hareket, fleksör tendonun, tendon kılıfı içindeki erken hareketine izin vererek yapışıkıkların en aza indirilmesini sağlar. Ancak, yine de egzersiz sırasında dikkatli olunmalıdır. Dirençli egzersiz bandiyla dorsifleksiyon, inversiyon ve eversiyon yönündeki egzersizlere başlanır. Beşinci haftadan itibaren, oturma sırasında yavaşça topuk kaldırma egzersizi yapılabilir.

Beşinci haftadan itibaren, dinamik stabilite sağlayan nöromusküler egzersizlere geçilir. Oturmada, farklı yüzeylerde dorsi-plantar fleksiyon egzersizleri ve wooble board ile stabilizasyon çalışılabilir (Şekil 1).

Alt ekstremite için; düz bacak kaldırma egzersizi ile yan yatışta kalça abduksiyon hareketlerine, botla statik bisiklet sürme ile açık kinetik diz ve kalça fleksiyon egzersizleri eklenir. 


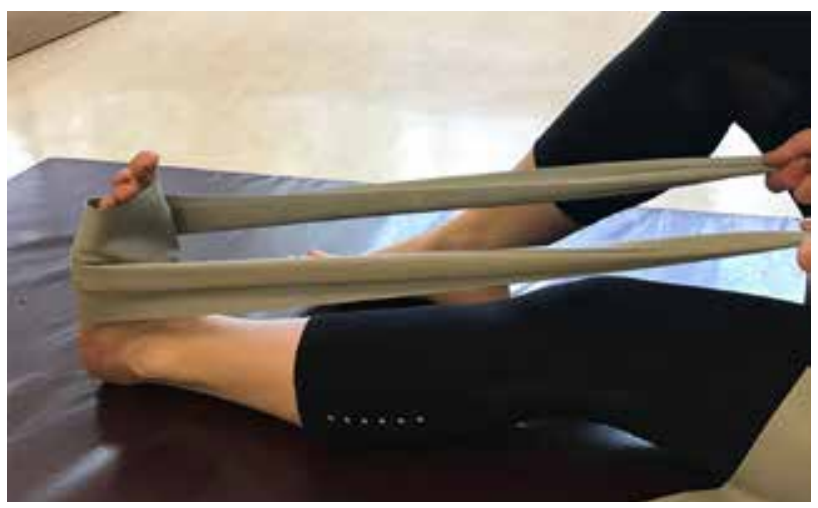

Şekil 2. Bantla Aşil tendonu germe.

Bu dönemde, botla birlikte koltuk değnekleri kullanılarak, hastanın tolere edebildiği kadar ağırlık aktarılır. Hasta, herhangi bir rahatsızlık duymadan ayağı üzerine ağılık vermeyi tolere edene kadar koltuk değneği kullanmalıdır. Hasta, ağılık vermeyi rahatıkla tolere edebildiğinde koltuk değneği bırakılır; bununla birlikte, ödem ve hassasiyeti belirgin şekilde azaldığında rehabilitasyonun ara dönemi başlar.

\section{Ara Dönem (6-14 hafta)}

Ara dönemde amaç, normal yürüme mekaniklerini kazandırmak ve fonksiyonel aktivitelerin yeniden düzgün bir şekilde yapılmasını sağlamaktır.

Bot çıkarılarak, ambulasyon botsuz yapılır. Duruma göre ayakkabı içine yükseklik yerleştirilebilir.

Ayak bileği bir havlu ya da bantla tam dorsifleksiyona götürülerek gerilebilir. Ayakta durma sırasında, bacak düzken veya bacak hafif öne bükülü hafif germe yapılabilir (Şekil 2). Bu dönemin özellikle erken safhalarında aşırı gerginlik oluşturmamaya dikkat edilmelidir.

Dirençli egzersiz bandıyla dört yönde (dorsfleksiyon, plantarflkesiyon, inversiyon, eversiyon) kuvvetlendirme yapılabilir (Şekil 3). Çift ayak parmak ucuna yükselme 7.-8. haftalarda yapılabilir.

Hastanın fonksiyonel düzeyine uygun olarak nöromusküler egzersizler ve fonksiyonel aktivitelerle birlikte kapalı kinetik ve açık kinetik egzersizler, dereceli ilerletilerek yaptırılabilir. Örneğin; oturmada bilateral topuk kaldırma ya da ellerle destek alırken çift ayak parmak ucuna yükselme yapılabilir.

Statik bisiklette çalışma, su içi egzersiz ve yürümenin yapıldığı akuaterapi, yapılabilir.

Leg press egzersizi, öne ve yana adım alma, basamağa adım alma egzersizleri ile kapalı ve açık kinetik olarak hamstring kaslarına yönelik fonksiyonel egzersizler uygulanabilir.
Botun çıkarılması ile birlikte, normal yürüyüşün kinetik ve kinematik özelliklerinin kazandırılması için yürüme eğitimine başlanmalıdır. Aşil tendon cerrahisi sonrası yürüyüşte biyomekanik değişikliklerin ve yürüyüş paterninin incelendiği bir çalışmada, ayak bileği hareketleri ile tibialis anterior ve soleus kasları kas koordinasyonunda adaptif değişikliklerin görüldüğü belirtilmiştir. ${ }^{[20]}$ Yürüme aktivitesi kazandırıldığında, dönemin sonunda hastanın durumuna göre hafif koşu (jogging) eğitimine geçilir.

Fizyoterapist gözetiminde denge eğitimi ve propriyoseptif eğitime başlanır ve eğitim ilerletilir (Şekil 4).

Duyu motor entegrasyonu arttırmada düz bir hat üzerinde tandem yürüyüşü, geriye adım alarak yürüme, tek ayak üzerinde denge, tilt ve wobble board'da denge çalışılabilir. Basamak çıkma ve inme aktivitelerine bu dönemde aşamalı olarak geçilir.

Hasta, ara dönem egzersizleri ağrısız bir şekilde yaptığında, ayağı tam eklem hareket açıklığına ulaştığında ve bilateral olarak topuk yükseltme yapabildiğinde, tek ayak üzerinde yüklenme simetrik olduğunda, bir sonraki faza geçilebilir.

\section{Geç Dönem (14-24 hafta)}

Rehabilitasyonun son aşaması olan bu faz, çok yönlü, hızlı, sık tekrarlı, daha çok kuwvet ve yüklenme gerektiren kompleks egzersizleri içerir. Bu fazda hedef, beceri ve çevikliği arttırmak ve spora özel eğitim ile spora dönüşü kolaylaştırmaktır.

Don ve ark. yaptıkları çalışmada, tibialis anterior ve soleus kaslarında konsantrik kasılmadaki defisitin cerrahi sonrası 12. ay, eksentrik kasılma paterninde ise post-op 24. aya kadar devam ettiğini belirtmişlerdir. ${ }^{[20]} \mathrm{Bu}$ nedenle, opere edilen bölgedeki kas aktivasyonunu geliştirmek ve kuvveti arttırmak için, konsantrik yüklenmeye dayanan egzersizlere devam ederken, Aşil tendonunu eksentrik olarak yükleyen egzersizlere de bu dönemde geçilir. Rehabilitasyonun ileri safhalarında olunsa dahi, bu egzersizler öncelikle ağırlık aktarılmayan pozisyonlarda elle direnç verilerek, sabit bir ağırlık ya da dirençli bantlarla yapılmalıdır. Sonra, dereceli olarak ağırık aktarılan, yapılan bir hareketin parçasını oluşturan eksentrik egzersizlere geçilebilir. Bilateral topuk yükseltme ve tek taraf üzerinde topuk yükseltme egzersizleri, öne ve yana hamle egzersizleri yapılabilir. Dirençli bantlarla ya da ağırlıklarla (toplar ya da ağırlık torbaları) gövdeyi çaprazlayan core stabilizasyon egzersizleri yapılabilir (Şekil 5).

Ara dönem sonuna doğru ve geç dönemden itibaren gravite azaltılarak leg press egzersizi ve pliyometrik egzersizler yapılabilir (Şekil 6). 


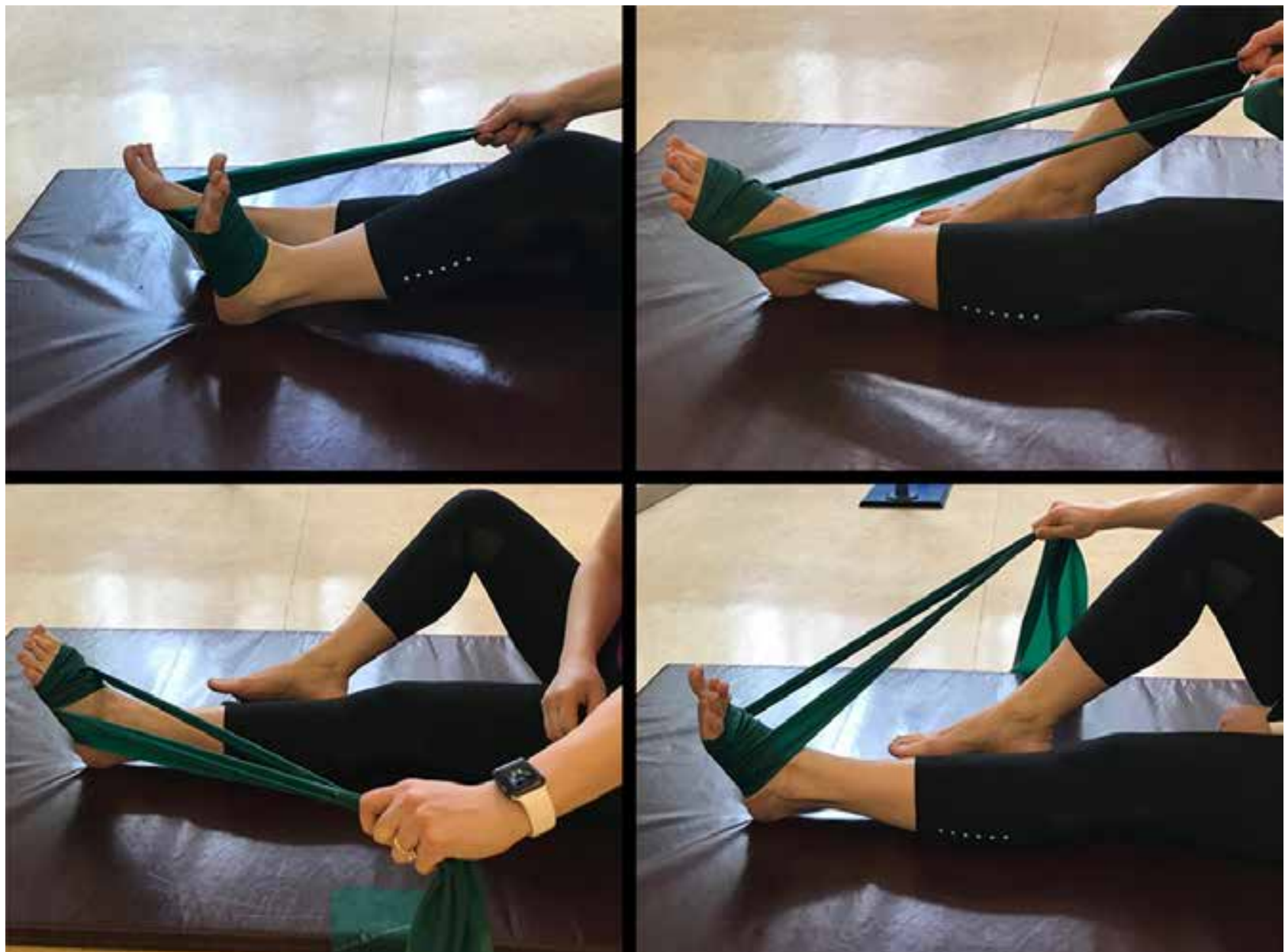

Şekil 3. Dirençli egzersiz bandı ile dört yönde kuvvetlendirme eğitimi.

\section{Spora Dönüş (24-52 hafta)}

Aşil tendon rüptürlerinin iyileşmesi ve rehabilitasyonundan sonra rekabet ve rekreasyon sporlarına dönüş yaygın gözükmekle beraber, yapılan çalışmalarda spora dönüş oranlarında farklılıklar görülmektedir. Hastanın spora dönüşü; hastanın cinsiyetine, yaralanma düzeyine, yaptığı spora, profesyonellik durumuna, hastanın psikolojik durumuna, yapılan cerrahi uygulamaya ve uygulanan tedavilere göre değişmektedir. Çalışmalarda, önceki aktivite ve katılım düzeyine genellikle \%75 ile \%100 arasında bir geri dönüş aralığı gösterilmiştir. ${ }^{[21]}$ Spora dönüş zamanı ortalama olarak 5 ile 7 ay arasında bulunmuştur. Amerikan Futbol Ligi'ndeki futbolcularda Aşil tendon cerrahisi sonrası lige dönüş oranı \%75'ten az olarak bulunmuştur. ${ }^{[22]}$ Spora dönüşü yürüyüş ve yüklenmedeki biyomekanik değişiklikler sonrası gelişen diz problemleri, karşı taraf Aşil tendinopatisi veya rüptürü (\%6) gibi ek kas-iskelet sistemi patolojileri de etkileyebilmektedir. ${ }^{[16,23]}$
Spora dönüş öncesi 12.-14. haftada hastayı değerlendirmek için; Ayak ve Ayak Bileği Engellilik İndeksi (Foot and Ankle Disability Index -FADI), Ayak ve Ayak Bileği Engellilik Indeksi Spor (Foot and Ankle Disability Index Sport), Alt Ekstremite Fonksiyon Ölçeği (Lower Extremity Functional Scale -LEFS) ve Aşil Tendon Toplam Rüptür Skoru (Achilles Tendon Total Rupture Score ATRS) uygulanabilir. Özellikle 3. aydaki Aşil Tendon Toplam Rüptür Skoru (ATRS) ile hastanın spora dönme ihtimalinin tahmin edebileceği belirtilmiştir. ${ }^{[24]}$

Hastalar fiziksel olarak spor aktivitelerine geri dönebilir durumda olsalar bile, yeniden rüptür oluşma korkusu, bireyin yaralandığı spor aktivitesinden kaçınmasına neden olabilir. Bu nedenle, spora dönüş fazında hastanın hareket korkusu da değerlendirilmeli ve rehabilitasyon programı bu yönüyle de geliştirilmelidir.

Cerrahi sonrası 3 ile 6 ay arasındaki dönem, kurvet ve fonksiyonel kazanımların en yüksek olduğu dönemdir; ancak iyileşme bir yıl sonraya kadar devam eder. 


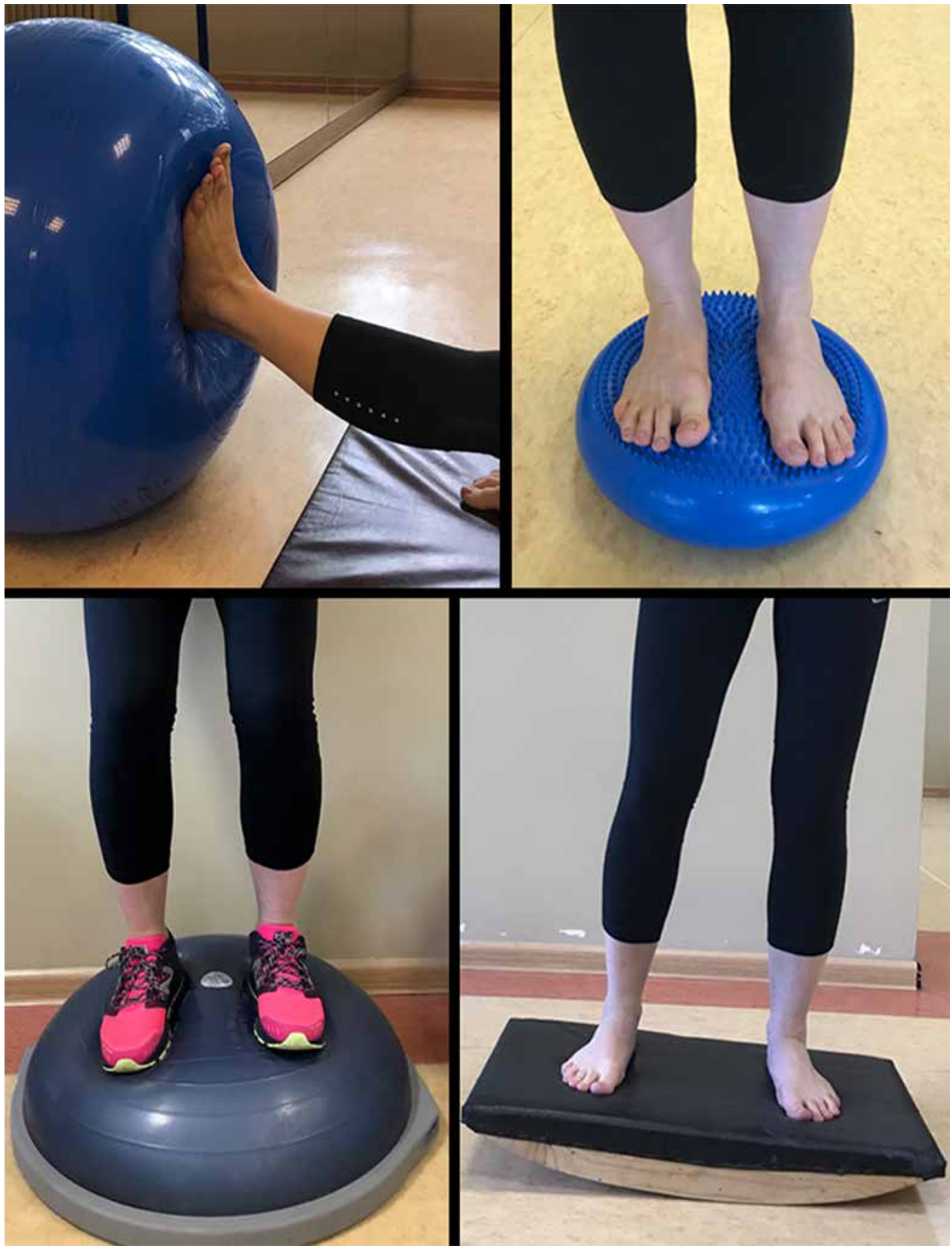

Şekil 4. Erken dönemde propriyoseptif eğitim. 


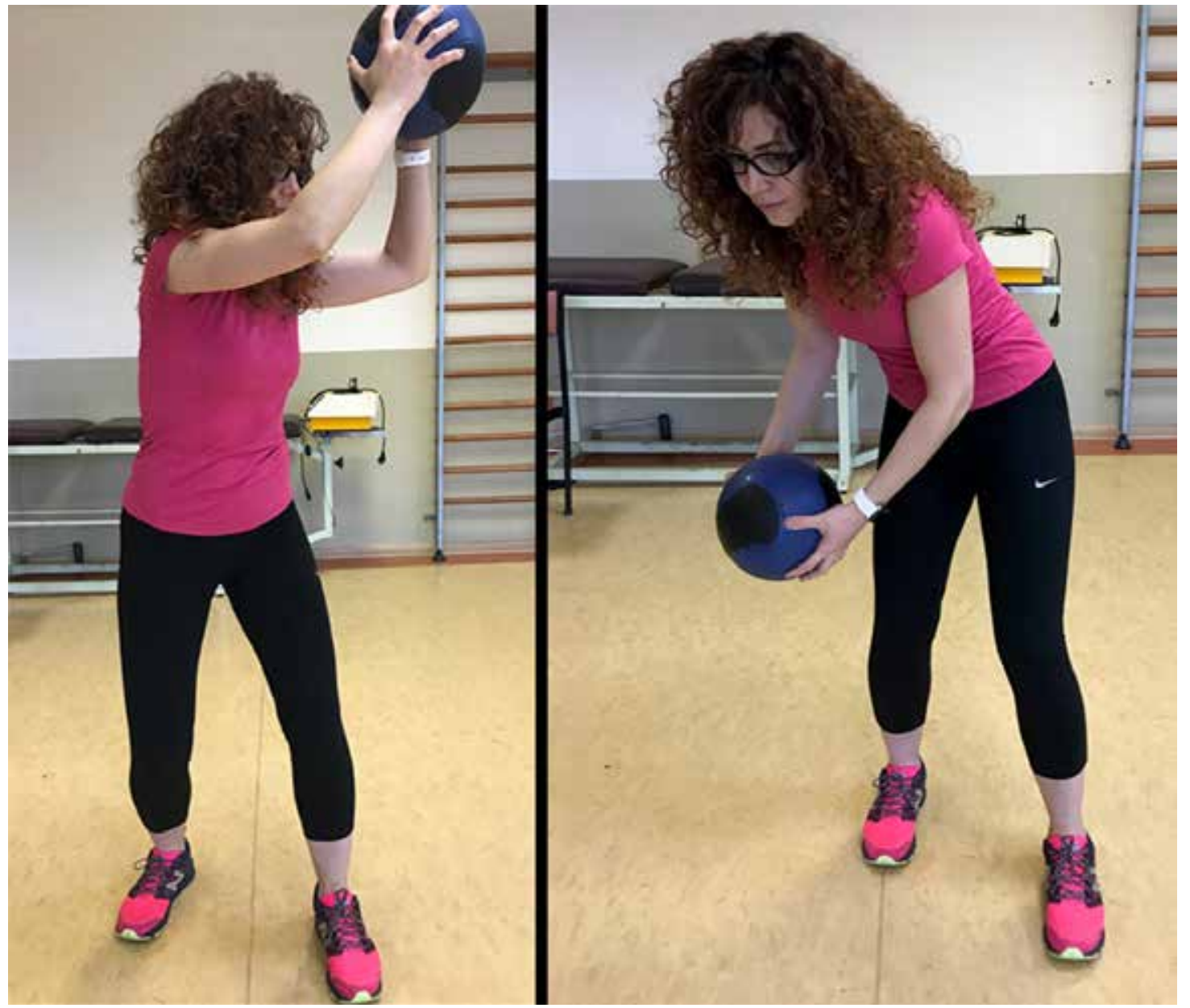

Şekil 5. Topla gövde stabilizasyonu.

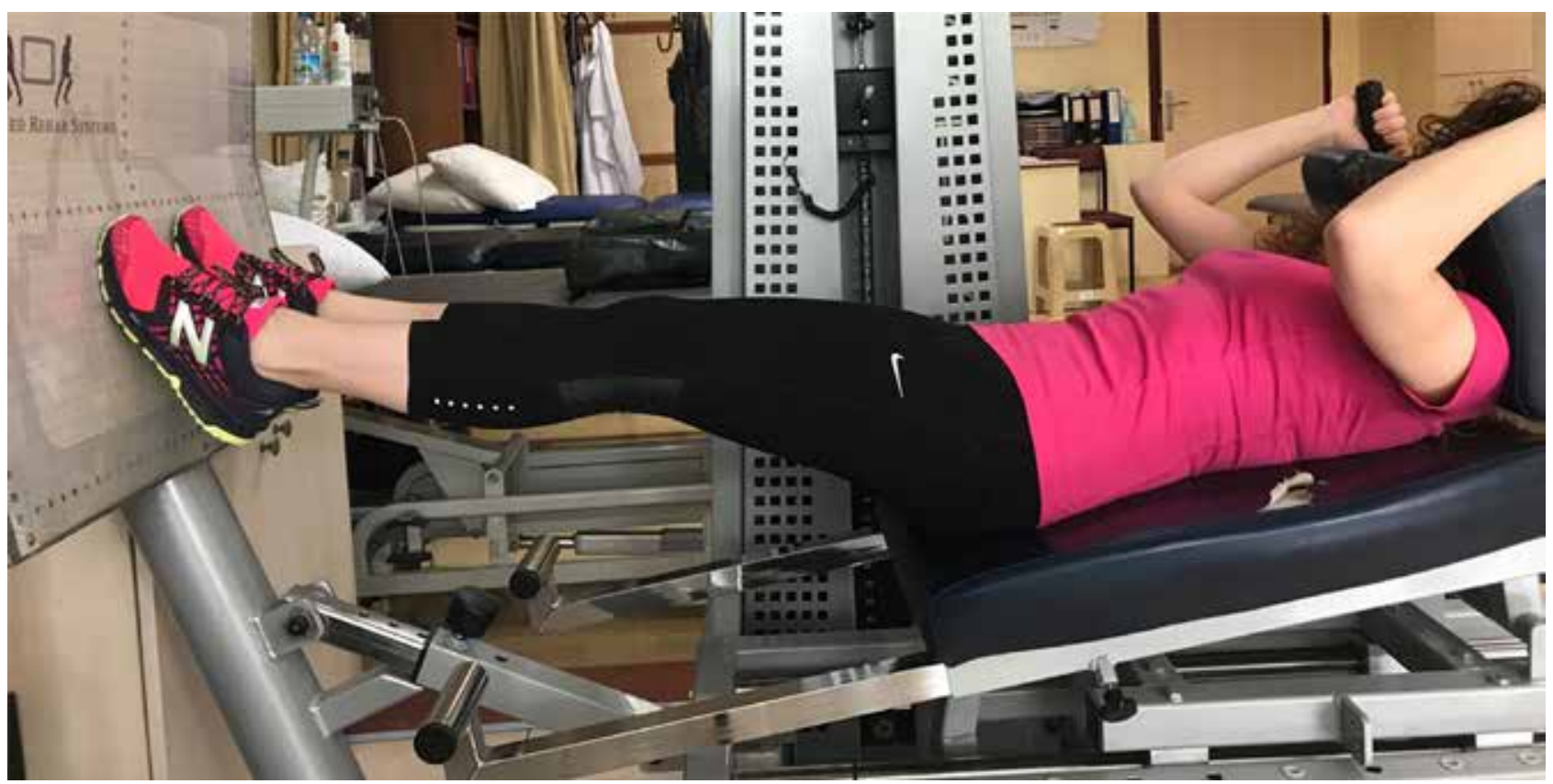

Şekil 6. Gravite etkisi azaltılarak pliyometrik eğitim. 
Normal taraf ile karşılaştırıldığında, etkilenen tarafta ileri dönemde hafif düzeyde bazı kalıcı kuvvet defisitleri görülebilmektedir. ${ }^{[25]}$

Genel olarak spora dönüş kriterleri şöyle sıralanabilir:

- Sporcular ağrısız olmalı; simetrik eklem hareket açıklığına ve kurvete sahip olmalı;

- Yürüme, kesme ve dönme hareketlerinde yürüyüş simetrisi olmalı;

- Atlama (yüklenme yokken) ve inişte (yükleme sırasında) alt ekstremite simetrisi olmalı;

- Tek ayak sıçrama mesafesi, lateral sıçrama mesafesi ve dikey sıçrama, etkilenmemiş ekstremitede gerçekleştirilen mesafenin veya yüksekliğin en az \%90'ı olmalıdır.

Spora dönüş için nöromusküler egzersizlere, kuvvetlendirme egzersizlerine ve propriyoseptif eğitime ilerleyici olarak devam edilir. Spor için gerekli sekme, sıçrama, atlama ile ani yer değiştirme içeren ileri egzersizlere geçilir (Şekil 7). Koşu ve sürat koşusu eğitimleri verilir.

Pertürbasyon eğitimi de, bu dönemde sportif performansı arttırmak ve yeniden yaralanma riskini önlemek için önemlidir. İleri dönemde pertürbasyon eğitiminin (Şekil 8) daha iyi fonksiyonel sonuçlar sağladığı ve refleks aktiviteleri geliştirdiği görülmektedir. Eklem yapılarındaki mekanoreseptörler uyarıldığında, gamma motor aktivitede artış görülür. Bu durum, kas iğciklerindeki uyarılabilirliği arttırarak yüksek seviyede bir hazır olma durumu oluşturur. ${ }^{[26]}$

Spora özgü eğitim rehabilitasyonun vazgeçilmezidir. Spora özgü eğitim sırasında bazı noktalarda dikkatli davranılmalıdır. Sporcularda ekstremitelerdeki hareket paternleri mutlaka spor performansı sırasında değerlendirilmelidir. Dinlenme sırasındaki ekstremite hereket paterni, spor performansı boyunca görülen paternden farklı olabilir. Sporcular, spora geri döndüklerinde, zıplama, iniş ve koşma sırasında ekstremite hareket paternlerinin simetrisi açısından yakından monitorize edilerek izlenmelidir. Ekstremite performansındaki asimetri, artan yorgunluk düzeyleriyle kendini daha belirgin olarak gösterebilir.

Herhangi bir spor için ihtiyaç analizi mutlaka yapılmalıdır. Fizyoterapist, söz konusu spor için gereklilikleri saptayabilmeli ve spora dönmeye hazırlıklı olmak için en uygun testleri ve egzersizleri belirleyebilmelidir. ${ }^{[27]}$

Aşil tendon cerrahilerinden sonra uygulanacak olan fonksiyonel rehabilitasyon programı Tablo 1'deki gibi özetlenebilir.

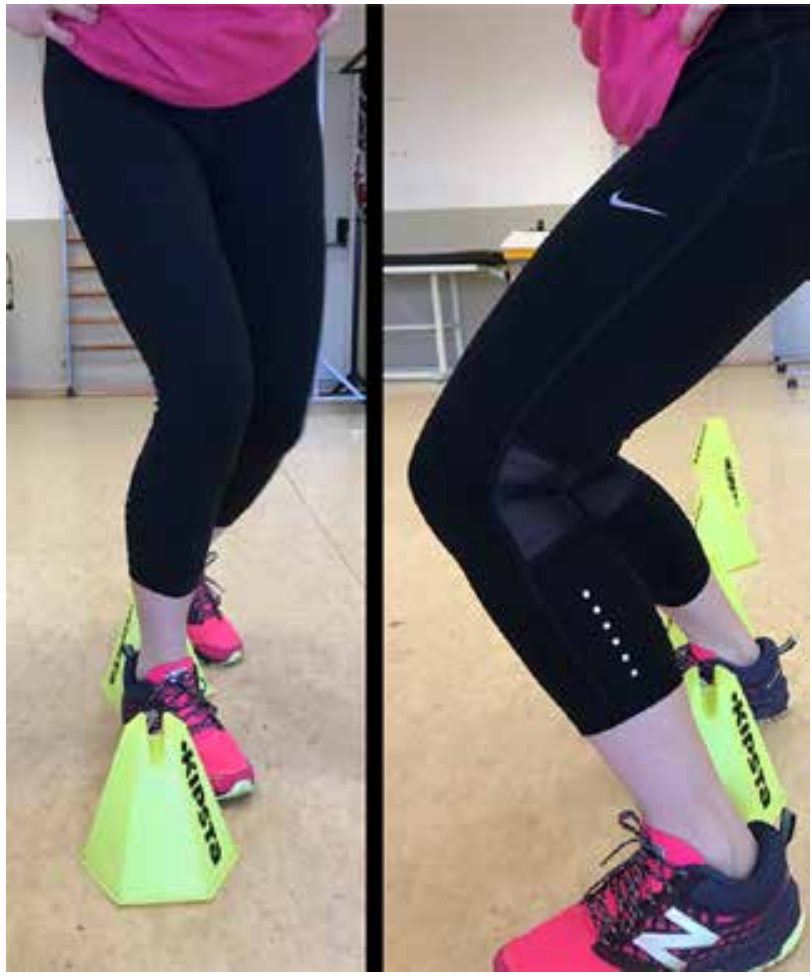

Şekil 7. Yer değiştirme ve engeller arası yan sıçrama eğitimi.

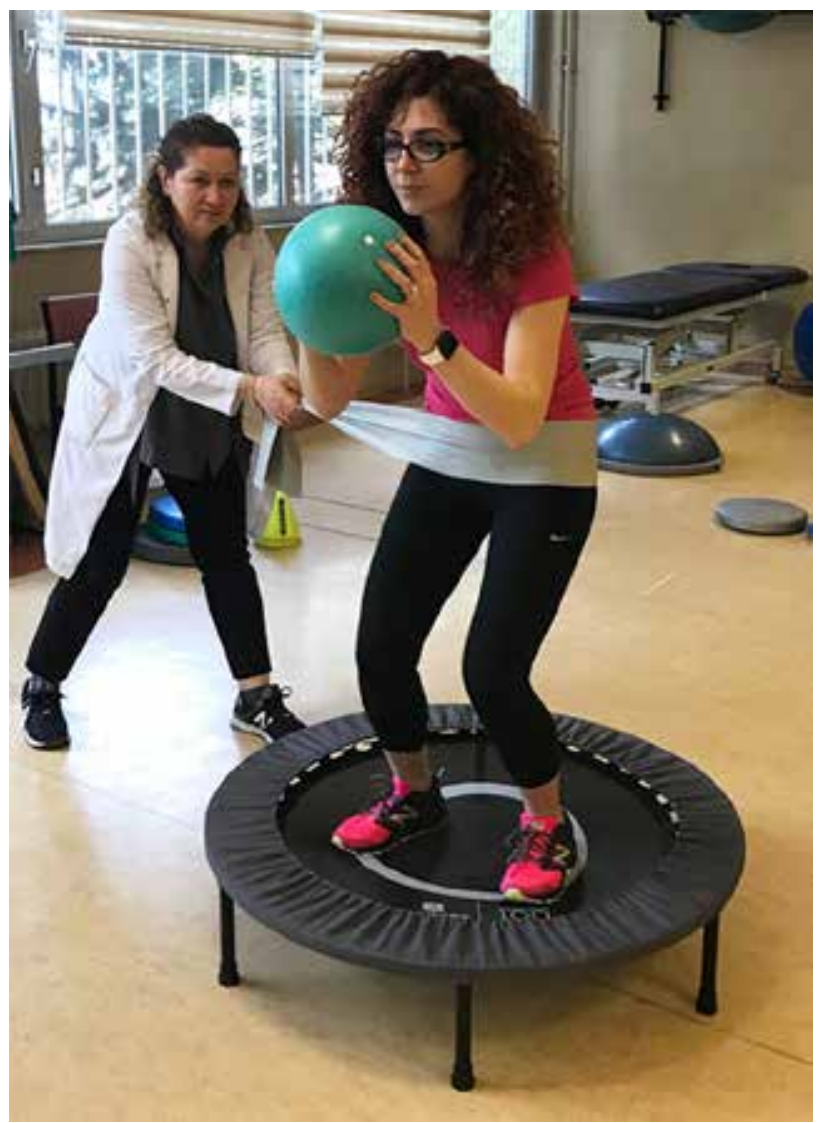

Şekil 8. Pertürbasyon eğitimi. 
Tablo 1. Aşil tendon cerrahilerinden sonra uygulanacak olan fonksiyonel rehabilitasyon programı Cerrahi Sonrası Erken Dönem (0-2 hafta)

Splint (24 saat)

Ağırlık aktarımı yok. Splint devam ya da yürüme botu (ayak ekin pozisyonunda) ve koltuk değnekleri ile (24 saat)

Dorsifleksiyon hareketi için ayak nötral pozisyonuna ulaşmayacak şekilde pasif eklem hareket açıklık egzersizleri

Ayak bileği aktif eklem hareket açıklı̆̆ı egzersizleri (dorsifleksiyon, eversiyon, inversiyon yönlerinde)

Eklem mobilizasyonu (Grade I)

Kriyoterapi

Elektrik stimülasyonu (enterfaransiyel akım, diadinamik akım, TENS... vb.)

İzometrik egzersizler (dorsifleksiyon, inversiyon, eversiyon)

\section{Erken Dönem (2-6 Hafta)}

Yürüme botu (20'lik plantar fleksiyon, $2 \mathrm{~cm}$ yükseklik)

Koltuk değnekleri ile hastanın tolere edebildiği ağılık, dönemin sonunda koltuk değnekleri bırakılır

Kriyoterapi, elektrik stimülasyonu (enterfaransiyel akım, diadinamik akım, TENS... vb.)

Dorsifleksiyon hareketi için ayak nötral pozisyonunu aşmayacak şekilde pasif eklem hareket açıklık egzersizleri (plantar fleksiyon, inversiyon, eversiyon

Her yönde ayak bileği aktif eklem hareket açıklığı egzersizleri (dorsifleksiyon, plantar fleksiyon, eversiyon, inversiyon yönlerinde)

İzometrik egzersizler (tüm yönlerde)

Egzersiz bandı ile dirençli egzersizler (dorsifleksiyon, inversiyon, eversiyon)

Oturmada yavaşca topuk kaldırma (5. haftadan itibaren)

Kalça ve diz eklemleri için dirençli açık ve kapalı kinetik zincir egzersizleri

Yürüme botu içinde sırt duvara dayalı mini squat

Statik bisiklet

Eklem mobilizasyonu (Grade I - Grade II)

Skar mobilizasyonu

Yürüme botu ile yürüyüş eğitimi

\section{Ara Dönem (6-14 hafta)}

Yürüme botu çıkarılır (duruma göre 8 . haftaya kadar ayakkabı içine yükseklik)

Egzersiz bandı ile dirençli egzersizler (tüm yönlerde)

Tüm hareketler için ilerleyici dirençli egzersizler

Oturma sırasında topukları kaldırma

Basamak çıkma ve inme egzersizleri

Akuaterapi

Yürüme eğitimi

Kapalı kinetik zincirde Aşil germe egzersizleri

Step-up egzersizi

Vücut ağırlı̆ı ile squat ve hamle egzersizleri

Leg press egzersizi

Tek ayak üzerinde durma ve denge eğitimi

Oturmada wobble board'la eğitim

Açık kinetik halka Aşil egzersizleri

Oturmada bilateral topuk yükseltme

Tek ayak denge ve tek ayak uzanma egzersizleri

Yürümeden hafif koşuya (jogging'e) geçiş

\section{Geç Dönem (14-24 hafta)}

Tek ayakta parmak ucuna yükselme

Tek ayak üzerinde squat

Hafif koşudan, koşuya ve sürat koşusuna geçiş

Pliyometrik egzersizler (20. haftadan sonra)

Çeviklik egzersizleri ve spora özel eğitimler

Pertürbasyon eğitimi

Profesyonel sportif hareketler (20.-24. hafta)

\section{Spora Dönüş (24-52 hafta)}

Hala var olan bozukluklara yönelik bireysel güç ve esneklik programı

Koşu ve sürat koşusu eğitimi

Pliyometrik egzersizler

Pertürbasyon eğitimi

Çeviklik eğitimi ve spora özel eğitim (sekme - sıçrama - atlama)

Spora dönüş 


\section{Teşekkür}

Yazının hazırlanması ve fotoğrafların çekimindeki katkılarından dolayı Uz. Fzt. Asude Arık’a teşekkür ederiz.

\section{KAYNAKLAR}

1. Suchak AA, Bostick GP, Beaupré LA, D'arcy CD, Jomha NM. The influence of early weight-bearing compared with nonweight-bearing after surgical repair of the Achilles tendon. J Bone Joint Surg Am 2008;90(9):1876-83. Crossref

2. Zhao JG, Meng XH, Liu L, Zeng XT, Kan SL. Early functional rehabilitation versus traditional immobilization for surgical Achilles tendon repair after acute rupture: a systematic review of overlapping meta-analyses. Sci Rep 2017;7:39871. Crossref

3. Marti R, Weber B. Rupture of the achilles tendon - functional after care. Helv Chir Acta 1974;41(1-2):293-6.

4. Mortensen HM, Skov O, Jensen PE. Early motion of the ankle after operative treatment of a rupture of the Achilles tendon. A prospective, randomized clinical and radiographic study. J Bone Joint Surg Am 1999;81(7):983-90.

5. Suchak AA, Spooner C, Reid DC, Jomha NM. Postoperative rehabilitation protocols for Achilles tendon ruptures: a metaanalysis. Clin Orthop Rel Res 2006;445:216-21. Crossref

6. Enwemeka CS. Functional loading augments the initial tensile strength and energy absorption capacity of regenerating rabbit Achilles tendons. Am J Phys Med Rehabil 1992;71(1):31-8.

7. Enwemeka CS, Spielholz NI, Nelson AJ. The effect of early functional activities on experimentally tenotomized Achilles tendons in rats. Am J Phys Med Rehabil 1988;67(6):264-9.

8. Rantanen J, Hurme T, Kalimo $\mathrm{H}$. Calf muscle atrophy and Achilles tendon healing following experimental tendon division and surgery in rats. Comparison of postoperative immobilization of the muscle-tendon complex in relaxed and tensioned positions. Scand J Med Sci Sports 1999;9(1):57-61.

9. Kangas J, Pajala A, Ohtonen P, Leppilahti J. Achilles tendon elongation after rupture repair: a randomized comparison of 2 postoperative regimens. Am J Sports Med 2007;35(1):5964. Crossref

10. Brumann M, Baumbach SF, Mutschler W, Polzer $\mathrm{H}$. Accelerated rehabilitation following Achilles tendon repair after acute rupture - Development of an evidence-based treatment protocol. Injury 2014;45(11):1782-90. Crossref

11. Maffulli N, Tallon C, Wong J, Lim KP, Bleakney R. Early weightbearing and ankle mobilization after open repair of acute midsubstance tears of the achilles tendon. Am J Sports Med 2003;31(5):692-700. Crossref

12. Huang J, Wang $C$, Ma X, Wang X, Zhang C, Chen L. Rehabilitation regimen after surgical treatment of acute Achilles tendon ruptures: a systematic review with metaanalysis. Am J Sports Med 2015;43(4):1008-16. Crossref

13. Kerkhoffs GM, Struijs PA, Raaymakers EL, Marti RK. Functional treatment after surgical repair of acute Achilles tendon rupture: wrap vs walking cast. Arch Orthop Trauma Surg 2002;122(2):102-5. Crossref
14. McCormack R, Bovard J. Early functional rehabilitation or cast immobilisation for the postoperative management of acute Achilles tendon rupture? A meta-analysis of randomised controlled trials. Br J Sports Med 2015;49(20):1329-35. Crossref

15. Jasko JJ, Brotzman SB, Giangarra CE. Achilles Tendon Rupture. In: Giangarra C, Manske R, editors. Clinical Orthopaedic Rehabilitation: A Team Approach E-Book. Philadelphia, PA: Elsevier; 2018. pp.299-302.

16. Follak N, Ganzer D, Merk H. The utility of gait analysis in the rehabilitation of patients after surgical treatment of Achilles tendon rupture. Eur J Orthop Surg Traumatol 2002;12(2):905. Crossref

17. Heikkinen J, Lantto I, Piilonen J, Flinkkilä T, Ohtonen P, Siira P, Laine V, Niinimäki J, Pajala A, Leppilahti J. Tendon Length, Calf Muscle Atrophy, and Strength Deficit After Acute Achilles Tendon Rupture: Long-Term Follow-up of Patients in a Previous Study. J Bone Joint Surg Am 2017;99(18):150915. Crossref

18. Twaddle BC, Poon P. Early motion for Achilles tendon ruptures: is surgery important? A randomized, prospective study. Am J Sports Med 2007;35(12):2033-8. Crossref

19. Kleinert H, Kutz J, Atasoy E, Stormo A. Primary repair of flexor tendons. Orthop Clin North Am 1973;4(4):865-76.

20. Don R, Ranavolo A, Cacchio A, Serrao M, Costabile F, lachelli M, Camerota F, Frascarelli M, Santilli V. Relationship between recovery of calf-muscle biomechanical properties and gait pattern following surgery for achilles tendon rupture. Clin Biomech (Bristol, Avon) 2007;22(2):211-20. Crossref

21. Jallageas R, Bordes J, Daviet J-C, Mabit C, Coste C. Evaluation of surgical treatment for ruptured Achilles tendon in 31 athletes. Orthop Traumatol Surg Res 2013;99(5):577-84. Crossref

22. Jack RA, Sochacki KR, Gardner SS, McCulloch PC, Lintner DM, Cosculluela PE, Varner KE, Harris JD. Performance and Return to Sport After Achilles Tendon Repair in National Football League players. Foot Ankle Int 2017;38(10):1092-9. Crossref

23. Årøen A, Helgø D, Granlund OG, Bahr R. Contralateral tendon rupture risk is increased in individuals with a previous Achilles tendon rupture. Scand J Med Sci Sports 2004;14(1):30-3.

24. Hansen MS, Christensen M, Budolfsen T, Østergaard TF, Kallemose T, Troelsen A, Barfod KW. Achilles tendon Total Rupture Score at 3 months can predict patients' ability to return to sport 1 year after injury. Knee Surg Sports Traumatol Arthrosc 2016;24(4):1365-71. Crossref

25. Carmont MR, Silbernagel KG, Edge A, Mei-Dan O, Karlsson J, Maffulli N. Functional Outcome of Percutaneous Achilles Repair: Improvements in Achilles Tendon Total Rupture Score During the First Year. Orthopaedic Journal of Sports Medicine 2013;1(1):2325967113494584. Crossref

26. Kınıklı Gi, Erden Z. Bağ Yaralanmalarında Rehabilitasyon. İçinde: Tunay VB, Erden Z, Yıldız C, editörler. Hipokrat Alt Ekstremite Yaralanmalarında Rehabilitasyon. Ankara: Hipokrat Kitabevi; 2017.

27. Flint JH, Rosenthal MD, Rue J-PH. Achilles Tendon Injuries. In: Reider B, Davies G, Provencher MT, editors. Orthopaedic Rehabilitation of the Athlete: Getting Back in the Game. Philadelphia, PA. Elsevier; 2015. p.1385-425. 